\title{
Biosynthesis of compatible solutes in rhizobial strains isolated from Phaseolus vulgaris nodules in Tunisian fields
}

\author{
Cristina Fernandez-Aunión ${ }^{1 \dagger}$, Thouraya Ben Hamouda ${ }^{2 \dagger}$, Fernando Iglesias-Guerra ${ }^{3}$, Montserrat Argandoña ${ }^{1}$, \\ Mercedes Reina-Bueno ${ }^{1}$, Joaquín J Nieto ${ }^{1}$, M Elarbi Aouani ${ }^{2,4}$, Carmen Vargas ${ }^{1 *}$
}

\begin{abstract}
Background: Associated with appropriate crop and soil management, inoculation of legumes with microbial biofertilizers can improve food legume yield and soil fertility and reduce pollution by inorganic fertilizers. Rhizospheric bacteria are subjected to osmotic stress imposed by drought and/or $\mathrm{NaCl}$, two abiotic constraints frequently found in semi-arid lands. Osmostress response in bacteria involves the accumulation of small organic compounds called compatible solutes. Whereas most studies on rhizobial osmoadaptation have focussed on the model species Sinorhizobium meliloti, little is known on the osmoadaptive mechanisms used by native rhizobia, which are good sources of inoculants. In this work, we investigated the synthesis and accumulations of compatible solutes by four rhizobial strains isolated from root nodules of Phaseolus vulgaris in Tunisia, as well as by the reference strain Rhizobium tropici CIAT $899^{\top}$.

Results: The most NaCl-tolerant strain was A. tumefaciens 10c2, followed (in decreasing order) by R. tropici CIAT 899 , R. leguminosarum bv. phaseoli 31c3, R. etli $12 \mathrm{a} 3$ and $R$. gallicum bv. phaseoli $8 \mathrm{a} 3 .{ }^{13} \mathrm{C}$ - and ${ }^{1} \mathrm{H}$-NMR analyses showed that all Rhizobium strains synthesized trehalose whereas $A$. tumefaciens 10c2 synthesized mannosucrose. Glutamate synthesis was also observed in $R$. tropici CIAT 899, R. leguminosarum bv. phaseoli 31c3 and A. tumefaciens 10c2. When added as a carbon source, mannitol was also accumulated by all strains. Accumulation of trehalose in R. tropici CIAT 899 and of mannosucrose in A. tumefaciens 10c2 was osmoregulated, suggesting their involvement in osmotolerance. The phylogenetic analysis of the otsA gene, encoding the trehalose-6-phosphate synthase, suggested the existence of lateral transfer events. In vivo ${ }^{13} \mathrm{C}$ labeling experiments together with genomic analysis led us to propose the uptake and conversion pathways of different carbon sources into trehalose. Collaterally, the $\beta$-1,2-cyclic glucan from $R$. tropici CIAT 899 was co-extracted with the cytoplasmic compatible solutes and its chemical structure was determined.

Conclusions: The soil bacteria analyzed in this work accumulated mainly disaccharides in response to $\mathrm{NaCl}$ stress. We could not find a direct correlation between the trehalose content of the rhizobial strains and their osmotolerance, suggesting that additional osmoadaptive mechanism should be operating in the most $\mathrm{NaCl}-$ tolerant strain R. tropici CIAT 899.
\end{abstract}

\section{Background}

Rhizobium-legume symbiosis represents the most important nitrogen-fixing mechanism, which may have the potential to increase nitrogen input in arid and semi-arid ecosystems. However, biotic (i.e., pests or

\footnotetext{
* Correspondence: cvargas@us.es

+ Contributed equally

${ }^{1}$ Department of Microbiology and Parasitology, University of Seville, Spain
}

diseases), and abiotic (i.e., salinity, drought, high temperature or heavy metals) constraints limit legume crop production in arid and semi-arid lands, which are often located in developing countries [1]. Both drought and salinity impose osmotic stress, as a result of large concentrations of either salt or non-ionic solutes in the surrounding medium, with the resulting deficit of water [2]. The Rhizobium-legume symbiosis is highly sensitive to osmotic stress. Therefore strategies to improve the

\section{() Biomed Central}


symbiosis efficiency and legume production under this constraint should target both symbiotic partners, together with appropriate crop and soil management [1].

Rhizospheric rhizobia are subjected to frequent fluctuations in the osmolarity of their environment due to the succession of drought and rain periods, the exclusion of salts like $\mathrm{NaCl}$ from root tissues, the release of plant exudates, or the production of exopolymers by plant roots and rhizobacteria. In addition, rhizobia must also adapt to the osmotic situation during the infection process and in a nodule exchanging nutrients with the host plant [3]. Therefore, besides symbiotic efficiency, osmotolerance may constitute a competitive trait for either native or inoculant rhizobia, in order to persist in drought/salt-affected soils, and/or after the process of seed coat-mediated desiccation, and maybe to improve the colonization and/or infection process.

One of the main mechanisms of bacterial adaptation to hyperosmotic conditions is the intracytoplasmic accumulation of low molecular-weight organic osmolytes $[2,4]$. These molecules are termed compatible solutes because they do not interact with macromolecules in detrimental ways [5]. Compatible solutes are accumulated either by uptake from the environment (exogenous compatible solutes or osmoprotectants) or by de novo biosynthesis (endogenous compatible solutes). The diversity of compatible solutes is large but falls into a few major chemical categories, such as sugars (i.e., sucrose, trehalose), polyols (i.e,, sorbitol, mannitol), amino acids and derivatives (i.e. proline, glutamate, glutamine), betaines and ectoines [4]. It is very common for microorganisms to use a cocktail of compatible solutes, a strategy that allows the cell to adapt the compatible solute pool to different environmental injuries. Indeed, the role of compatible solutes goes beyond osmotic adjustment alone, to protection of cells and cell components from freezing, desiccation, high temperature and oxygen radicals $[4,6,7]$. On the other hand, hypoosmotic adaptation in gram-negative bacteria, including the Rhizobiaceae, involves the accumulation of periplasmic cyclic glucans, which appear to contribute substantially to periplasmic osmolarity $[3,8]$.

Among the Rhizobiaceae, the best studied species regarding osmoadaptation is Sinorhizobium meliloti one of the most common alfalfa microsymbionts. Specific concomitant accumulation of potassium and glutamate was found to be the primary response in S. meliloti to hyperosmotic stress [9]. Out of four potassium uptake systems found within the $S$. meliloti genome, Trk was shown to be the most important $\mathrm{K}^{+}$importer involved in the osmoadaptation of this bacterium [10]. By using ${ }^{13} \mathrm{C}$ nuclear magnetic resonance spectroscopy (a particularly useful technique for osmoadaptation studies because all types of organic compounds can be detected at once), it was shown that S. meliloti long term response to hyperosmotic stress involves the synthesis and accumulation of the dipeptide $\mathrm{N}$-acetylglutaminylglutamine amide and the disaccharide trehalose, the latter one specially when cells are subjected to severe osmotic stress $[3,11]$.

Trehalose is a non-reducing glucose disaccharide that is widespread in nature. It protects numerous biological structures against abiotic stresses including desiccation, oxidation, heat, cold, dehydration, and hyperosmotic conditions [6]. Recently, the importance of trehalose in osmotolerance and nodulation of their legume hosts by S. meliloti [12] and Bradyrhizobium japonicum [13] has been firmly established. Trehalose has shown to play also a major role in desiccation tolerance of $R$. leguminosarum bv. trifolii [14].

Common bean (Phaseolus vulgaris) is an important staple crop in the diets of people of Latin America, Asia, Africa, and other regions of the developing world. Paradoxically, despite common bean is a promiscuous legume able to form symbioses with a number of rhizobial species including R. tropici, $R$. etli, $R$. gallicum, $R$. leguminosarum $b v$. phaseoli or R. giardinii [15-17], it is considered as a poor nitrogen fixer, if compared to other grain legumes $[18,19]$. This problem has been attributed to the ineffectiveness of indigenous rhizobia [20] or to adverse abiotic conditions [21]. In a recent work, Suarez et al. [22] reported an increase in root nodule number and nitrogen fixation by $P$. vulgaris $\mathrm{cv}$. Negro Jamapa (a Mesoamerican cultivar) inoculated with a trehalose-6-phosphate synthase-overexpressing strain of $R$. etli. Thus, manipulating trehalose metabolism in $P$. vulgaris looks a promising strategy to improve plant tolerance to osmotic stress and grain yield. Compared to this body of knowledge on the osmoadaptation of these agronomically important rhizobacteria, little is known about the osmostress responses of rhizobial strains nodulating common bean in Africa. The purpose of the work described here was threefold. First, we used

${ }^{13} \mathrm{C}$-NMR to compare the osmoadaptive responses of three effective Rhizobium strains isolated from root nodules of $P$ vulgaris grown in Tunisian fields under rainfed conditions $[23,24]$ with that of the reference strain $R$. tropici CIAT $899^{\mathrm{T}}$, a Latin American isolate that has been shown to tolerate several abiotic stresses, including high temperature, low $\mathrm{pH}$, or salinity $[15,25,26]$. Despite a number of $R$. tropici CIAT 899 osmosensitive mutants has been characterized, none of them was affected in compatible solute synthesis $[26,27]$. In fact, the complete set of compatible solutes in this strain was unknown previously to this work. Second, we aimed to determine the osmoadaptive mechanism of Agrobacterium sp. 10c2 (proposed in this paper as $A$. tumefaciens 10c2), which was isolated from the same 
Tunisian common bean fields as the above strains [24]. Agrobacterium sp. 10c2 could not nodulate $P$. vulgaris per se, but it was able to colonize pre-formed $P$. vulgaris nodules [28] and to modulate, either positively or negatively, nodulation of common beans by native rhizobia [29]. Third, we focused on trehalose, which we found as the major compatible solute in the four Rhizobium strains. We determined the trehalose content of the strains and traced its biosynthetic pathway both molecularly and biochemically. Collaterally, the $\beta$-1,2-cyclic glucan from $R$. tropici CIAT 899 was co-extracted with the cytoplasmic compatible solutes when cells were grown at low salinity, and its chemical structure was determined by using a suite of one-dimensional and twodimensional NMR spectra and mass spectrometry.

\section{Results}

\section{Strain identity and phylogeny}

Strains $R$. gallicum bv. gallicum 8a3, R. etli 12a3, Agrobacterium sp. 10c2 and $R$. leguminosarum bv. phaseoli 31c3 were previously isolated by Mhamdi et al. [23] from nodules of $P$. vulgaris grown on neutral soil samples collected from North Tunisia. A preliminary strain affiliation was made upon RFLP analysis of the $16 \mathrm{~S}$ rRNA, nodC and nifH genes [24], and partial sequence of the $16 \mathrm{~S}$ rDNA and BLAST search for homologous sequences (for Agrobacterium sp. 10c2 [28]). To confirm the identity and phylogenetic position of the strains, we sequenced their nearly complete $16 \mathrm{~S}$ rDNA Figure 1 shows the phylogenetic tree constructed using the neighbor-joining method based on these sequences and those of closely related rhizobia obtained from GeneBank. Strains R. etli 12a3, R. gallicum bv. phaseoli 8a3, and Agrobacterium sp. 10c2 grouped with the $R$. etli, $R$. gallicum and $A$. tumefaciens type strains. On the basis of its phylogenetic relatedness to the type strain of $A$. tumefaciens, we propose strain Agrobacterium sp. 10c2 to be named as $A$. tumefaciens $10 \mathrm{c} 2$. R. leguminosarum bv. phaseoli 31c3 was in the same cluster as the type strains of $R$. leguminosarum bvs. trifolii and viciae, but in a separate branch. Interestingly, the type strain of $R$. leguminosarum bv. phaseoli, was in a separate group, close to the $R$. etli type strain. This lack of clustering between the type strains of $R$. leguminosarum bv. phaseoli and the other two biovars of $R$. leguminosarum was previously reported [30], and it was proposed that $R$. phaseoli should be retained as a separate species.

\section{Differences in halotolerance of the strains}

As a previous step to investigate the compatible solute content of the local and reference strains, we selected a suitable minimal medium for their growth and determined their tolerance to $\mathrm{NaCl}$. Growth was tested in two chemically defined minimal media (M79-I or MAS) with two different carbon sources $(20 \mathrm{mM}$ glucose or mannitol). Cell yield (as measured by turbidimetry) showed that $R$. gallicum bv. phaseoli $8 \mathrm{a} 3$ grew better in M79-I with glucose, $R$. leguminosarum bv. phaseoli 31c3 and $R$. etli $12 \mathrm{a} 3$ in M79-I with mannitol, and $R$. tropici CIAT 899 and $A$. tumefaciens 10c2 in MAS with mannitol (data not shown). Subsequently, cells were grown in $50 \mathrm{ml}$ of their optimal minimal media containing increasing $\mathrm{NaCl}$ concentrations up to $600 \mathrm{mM} \mathrm{NaCl}$. Cultures were incubated at $28^{\circ} \mathrm{C}$ and growth was monitored up to the stationary phase. The most salt-tolerant strain was $A$. tumefaciens $10 \mathrm{c} 2$, which grew well in MAS medium containing $400 \mathrm{mM} \mathrm{NaCl}$ and displayed optimal growth at $200 \mathrm{mM} \mathrm{NaCl}$ (Figure 2). A. tumefaciens 10c2 growth was totally impaired at $600 \mathrm{mM} \mathrm{NaCl}$ (not shown). The second most $\mathrm{NaCl}$-tolerant strain was $R$. tropici CIAT 899, which grew well in MAS medium containing up to $200 \mathrm{mM} \mathrm{NaCl}$ and showed optimal growth at $50 \mathrm{mM} \mathrm{NaCl}$. Strains $R$. leguminosarum bv. phaseoli 31c3, R. etli 12a3 and R. gallicum bv. phaseoli $8 \mathrm{a} 3$ were the most salt sensitive ones, showing optimal growth in basal M79-I medium with no extra salt added. $R$. leguminosarum bv. phaseoli $31 \mathrm{c} 3$ was slightly more salt-tolerant than $R$. etli $12 \mathrm{a} 3$ and $R$. gallicum bv. phaseoli 8a3. Growth of these three strains was severely impaired over $100 \mathrm{mM} \mathrm{NaCl}$ (Figure 2).

\section{Analysis of major intracellular solutes}

The differences found in salt tolerance of the strains prompted us to investigate and compare their compatible solute content. For this purpose, we analyzed cellular extracts by using ${ }^{1} \mathrm{H}$ - and ${ }^{13} \mathrm{C}$-NMR. The ${ }^{13} \mathrm{C}$-NMR spectrum of $R$. leguminosarum bv. phaseoli 31c3 grown in mannitol M79-I medium with $100 \mathrm{mM} \mathrm{NaCl}$ contained three sets of chemical shifts that were assigned to the disaccharide trehalose $(61.2,70.4,71.7,72.8,73.2$, and $93.9 \mathrm{ppm})$, the sugar alcohol mannitol (63.9, 70.0, and $71.6 \mathrm{ppm})$ and the amino acid glutamate (27.6, 34.2, $55.4,175.2$, and $181.9 \mathrm{ppm}$ ) (Figure 3A). Trehalose and mannitol, but not glutamate, were also majoritarily found in extracts from strain $R$. etli $12 \mathrm{a} 3$ cultivated in mannitol M79-I medium with $100 \mathrm{mM} \mathrm{NaCl}$ (Figure 3B). The identity of these three compatible solutes was confirmed by ${ }^{1} \mathrm{H}-\mathrm{NMR}$ analysis of extracts from the two strains (not shown).

When grown in MAS medium with $100 \mathrm{mM} \mathrm{NaCl}$ in the presence of mannitol, $R$. tropici CIAT 899 spectrum displayed three sets of resonances that could be assigned to trehalose, mannitol and glutamate, and a fourth set of six sugar carbon resonances (at 61.3, 69.5, 76.1, 77.0, 82.5, and $102.6 \mathrm{ppm}$ ) that could not be initially assigned to any known compound (Figure 4A). However, the presence of a signal with a chemical shift above $102 \mathrm{ppm}$, indicated $\beta$ configuration of a glucose unit. When the salt 


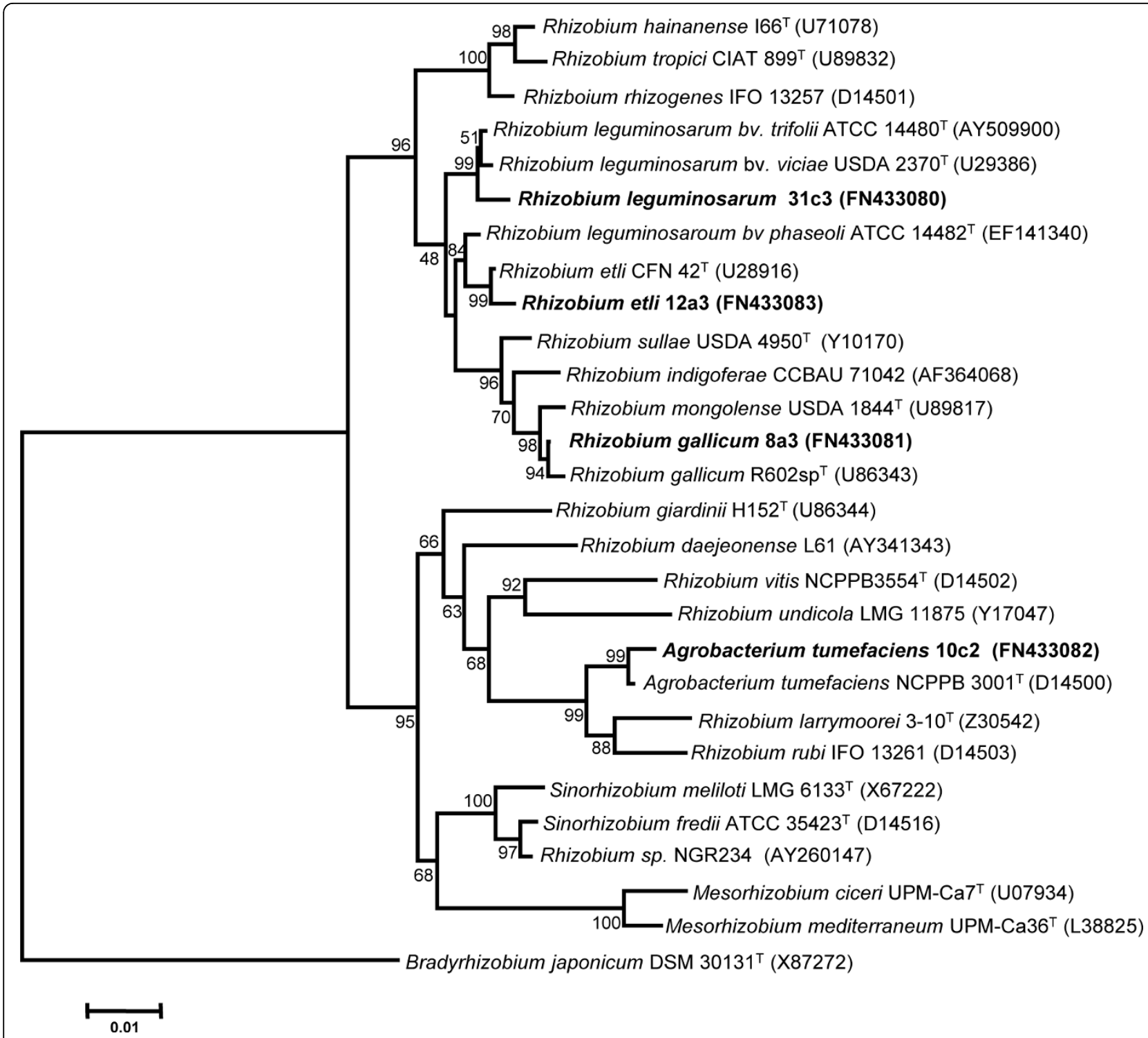

Figure 1 Identity and phylogeny of rhizobial strains isolated from common bean nodules. Neighbor-joining tree based on 16S rDNA sequences of the isolates and other related species of the family Rhizobiaceae. The tree is drawn to scale, with branch lengths in the same units as those of the evolutionary distances used to infer the phylogenetic tree. All positions containing alignment gaps and missing data were eliminated only in pairwise sequence comparisons. Bootstrap probabilities (as percentage) were determined from 1000 resamplings. Bar, 0.01 substitutions per nucleotide position. Note that the validated name of the genus Sinorhizobium is Ensifer [59].

concentration was raised up to $200 \mathrm{mM} \mathrm{NaCl}$ in the same medium, only chemical shifts due trehalose and glutamate were observed, whereas those corresponding to mannitol and the unknown sugar were not detected (Figure 4B). Trehalose, mannitol, and an unknown minoritary sugar showing a similar resonance pattern as the unidentified compound found in $R$. tropici CIAT 899, were detected in the ${ }^{13} \mathrm{C}$-NMR spectra of $R$. gallicum bv. phaseoli $8 \mathrm{a} 3$ grown in M79-I medium with $100 \mathrm{mM} \mathrm{NaCl}$ and mannitol (Figure 4C). However, mannitol was not accumulated in $R$. gallicum bv. phaseoli $8 \mathrm{a} 3$ cultivated in the same medium with glucose as a carbon source (Figure 4D), suggesting that mannitol accumulation depends on its transport, rather than synthesis, in this strain.

Figure 5 shows the ${ }^{13} \mathrm{C}$-NMR analysis of $A$. tumefaciens $10 \mathrm{c} 2$ grown in mannitol MAS medium with increasing salinity. At the lowest salt concentration tested $(100 \mathrm{mM}$ $\mathrm{NaCl}$ ), mannitol was the only intracellular solute detected (Figure 5A). However, above $100 \mathrm{mM} \mathrm{NaCl}$ mannitol was absent, and spectra contained five resonances attributed to glutamate and twelve resonances corresponding to the disaccharide mannosucrose ( $\beta$-fructofuranosyl- $\alpha$ - 


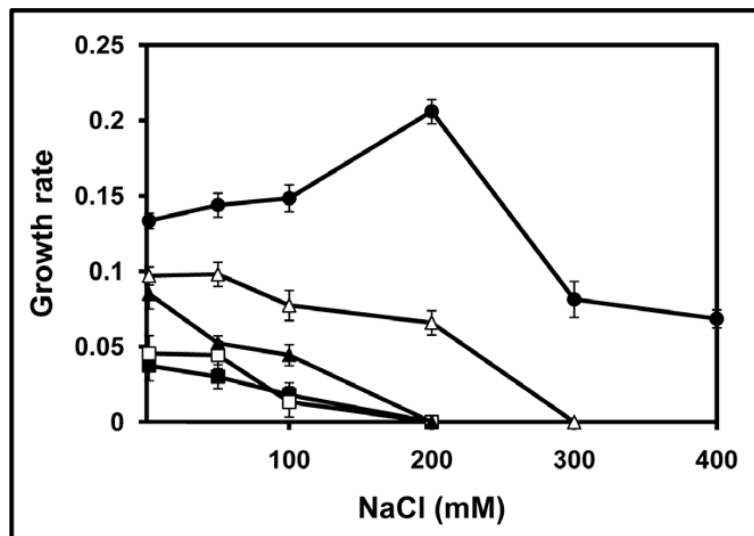

Figure 2 Effect of $\mathrm{NaCl}$ concentration on the growth rates of the strains isolated from common bean nodules. $R$. gallicum $8 a 3$ (-) was grown in M79-I with $20 \mathrm{mM}$ glucosa. R. etli 12a3 (ㅁ) and $R$. leguminosarum 31c3 (4) were grown in M79-I with $20 \mathrm{mM}$ mannitol, and $R$. tropici CIAT 899 (control) $(\Delta)$ and A. tumefaciens 10c2 (•) were grown in MAS with $20 \mathrm{mM}$ mannitol. Growth rates are expressed as $\triangle \mathrm{OD}_{600} / \mathrm{h}$. Values shown are the mean of two replicas of each condition in three independent experiments \pm SD (standard deviation).

mannopyranoside: 63.9, 64.3, 65.6, 69.7, 73.4, 74.3, 76.5, 77.2, 79.3, 84.6, 96.8, and 107.2 ppm) (Figures 5B and 5C). Identification of the latter was performed by comparison of the observed and published chemical shifts of this compound, which was reported to be accumulated by A. tumefaciens strain NT1 [31].

\section{Trehalose content of the rhizobial strains}

As the four Rhizobium strains which accumulated trehalose displayed different salt tolerance, we investigated if there was a correlation between their intracellular trehalose content and their tolerance to salinity. For this purpose, trehalose was quantified colorimetrically from cells grown up to early stationary phase in their optimal minimal medium with $0.1 \mathrm{M}$ (all strains) or $0.2 \mathrm{M} \mathrm{NaCl}$ (only CIAT 899) $\mathrm{NaCl}$. As illustrated in Figure 6, intracellular trehalose content of strains $R$. leguminosarum bv. phaseoli 31c3, R. etli $12 \mathrm{a} 3$ and $R$. gallicum bv. phaseoli $8 \mathrm{a} 3$ grown at $0.1 \mathrm{M} \mathrm{NaCl}$ ranged from 0.11 to 0.16 $\mu \mathrm{mol} / \mathrm{mg}$ protein. At the same salinity, cells of the more salt-tolerant $R$. tropici CIAT 899 accumulated ca. 0.03 $\mu \mathrm{mol}$ of trehalose per $\mathrm{mg}$ of protein, but they displayed a 3.2-fold higher trehalose content when they were grown at $0.2 \mathrm{M} \mathrm{NaCl}$, suggesting that trehalose accumulation in this strain is osmoregulated. However, even at $0.2 \mathrm{M} \mathrm{NaCl}$ trehalose levels of $R$. tropici CIAT 899 were equivalent to those of the more salt-sensitive strains $R$. leguminosarum bv. phaseoli 31c3 and R. gallicum bv. phaseoli $8 \mathrm{a} 3$ grown under their $\mathrm{NaCl}$ limiting conditions $(0.1 \mathrm{M} \mathrm{NaCl})$. The above data suggest that there is not a direct correlation between trehalose content of the strains and their salt tolerance. In addition, they suggest that, although trehalose accumulation in $R$. tropici CIAT 899 is osmoregulated, trehalose alone cannot account for the higher halotolerance of $R$. tropici CIAT 899.

\section{Isolation and phylogenetic analysis of the otsA gene}

Since all Rhizobium strains tested synthesized trehalose, we were interested to check if this occurs through the OtsA-OtsB pathway. This very well conserved route involves the transfer of glucose from UDP-glucose to glucose-phosphate to form trehalose-6-phosphate by trehalose-6-phosphate synthase (OtsA). Then, a trehalose-

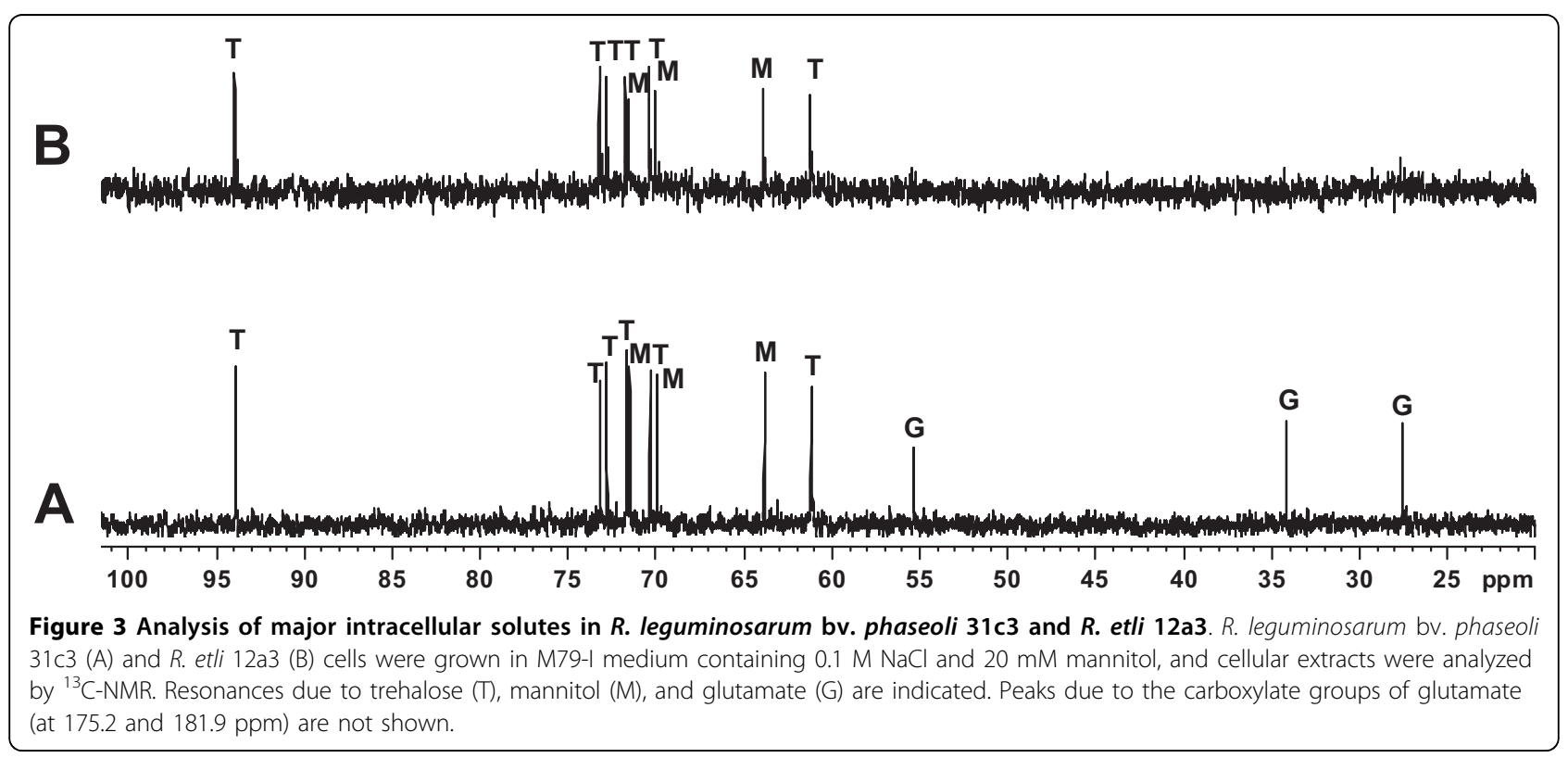




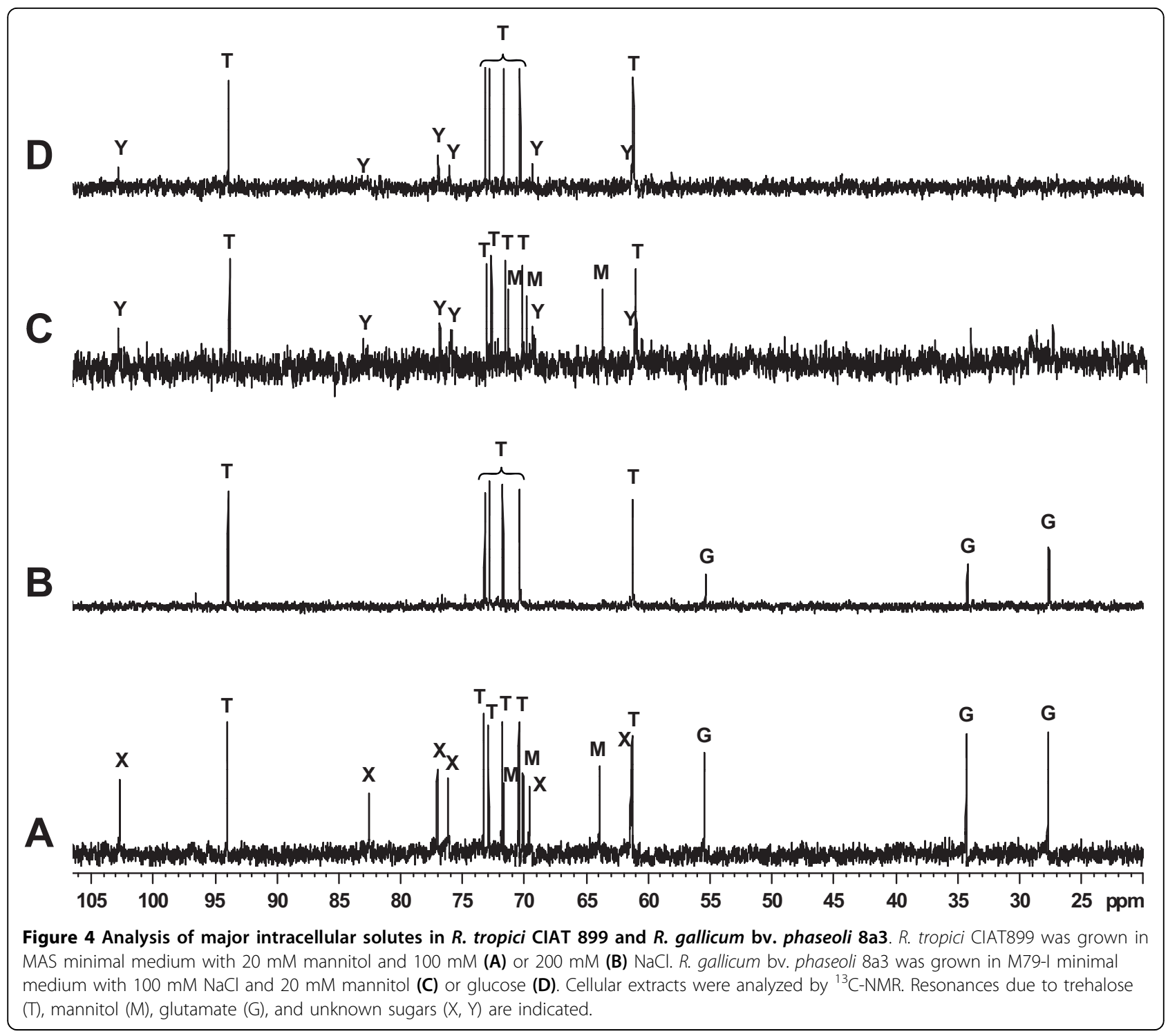

6-phosphate phosphatase (OtsB) dephosphorylates this intermediate to produce trehalose [32,33]. The ots $A$ genes of R. leguminosarum bv. trifolii [14], S. meliloti [12], R. etli [22] and B. japonicum [13] have been recently isolated. To check the presence of otsA in the genome of the Rhizobium strains, we designed oligonucleotides covering two very well-conserved regions and amplified the corresponding genes from genomic DNA of the selected strains. Single PCR products of ca. $1 \mathrm{~kb}$ were obtained from genomic DNAs of $R$. etli $12 \mathrm{a} 3, R$. gallicum bv. phaseoli $8 \mathrm{a} 3$ and $R$. leguminosarum bv. phaseoli 31c3 (by using the primers OTA1 and OTA2), and $R$. tropici CIAT 899 (by using the primers OTAS1 and OTAS2). As expected, A. tumefaciens 10c2 DNA was not amplified with any of the two otsA primer pairs.
The aligned OtsA proteins were subjected to phylogenetic analysis, and the resulting tree is shown in Figure 7. As expected, the OtsA proteins from $R$. tropici CIAT 899, R. etli 12a3, R. gallicum bv. phaseoli $8 \mathrm{a} 3$ and $R$. leguminosarum bv. phaseoli 31c3 grouped with OtsA proteins of $\alpha$ proteobacteria, but some incongruencies were found. For example, $R$. gallicum bv. phaseoli 8a3 OtsA was more related to the OtsA proteins of Sinorhizobium (i.e. S. meliloti 1021 or Rhizobium sp. NGR 234) than to those of $R$. etli or $R$. leguminosarum. In addition, $R$. etli $12 \mathrm{a} 3$ OtsA did not cluster with $R$. etli CFN 42 OtsA but with the OtsA proteins from $R$. leguminosarum bv. phaseoli 31c3 and $R$. leguminosarum bv. trifolii. From the above results, we suggest that the OtsA-OtsB pathway may be involved in trehalose synthesis in all strains tested. 

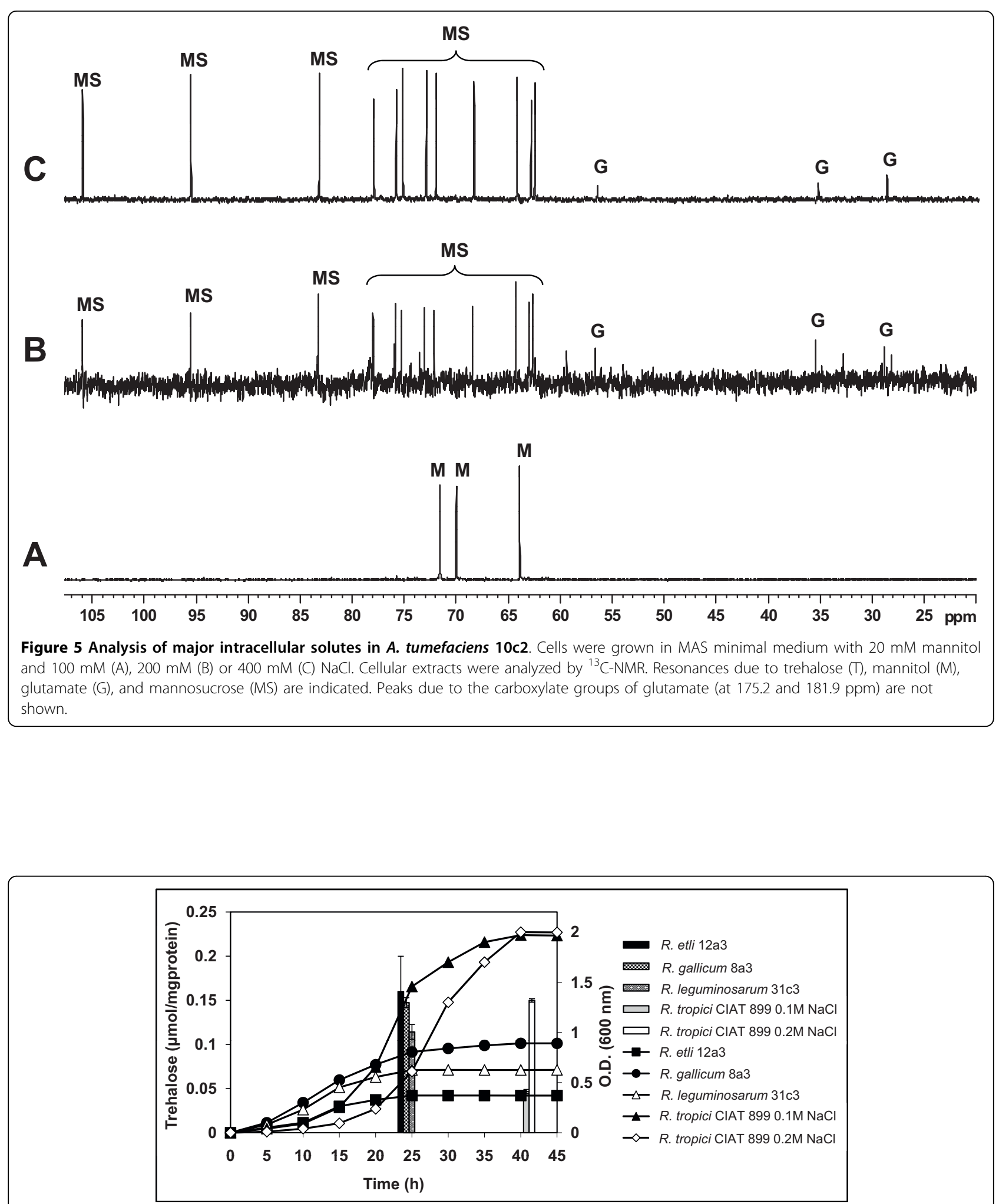

Figure 6 Trehalose accumulation by R. etli 12a3, R. gallicum bv. phaseoli 8a3, R. tropici CIAT 899, and R. leguminosarum bv. phaseoli 31c3. Cells were grown in their optimal minimal medium up to early stationary phase, and trehalose content was measured colorimetrically as described in Methods. For each strain, a growth curve under the same condition used to measure trehalose accumulation is shown. Histograms representing trehalose accumulation are place above the sampling time. Trehalose values shown are the mean of three replicas of each condition in two independent experiments \pm SD (Standard deviation). 


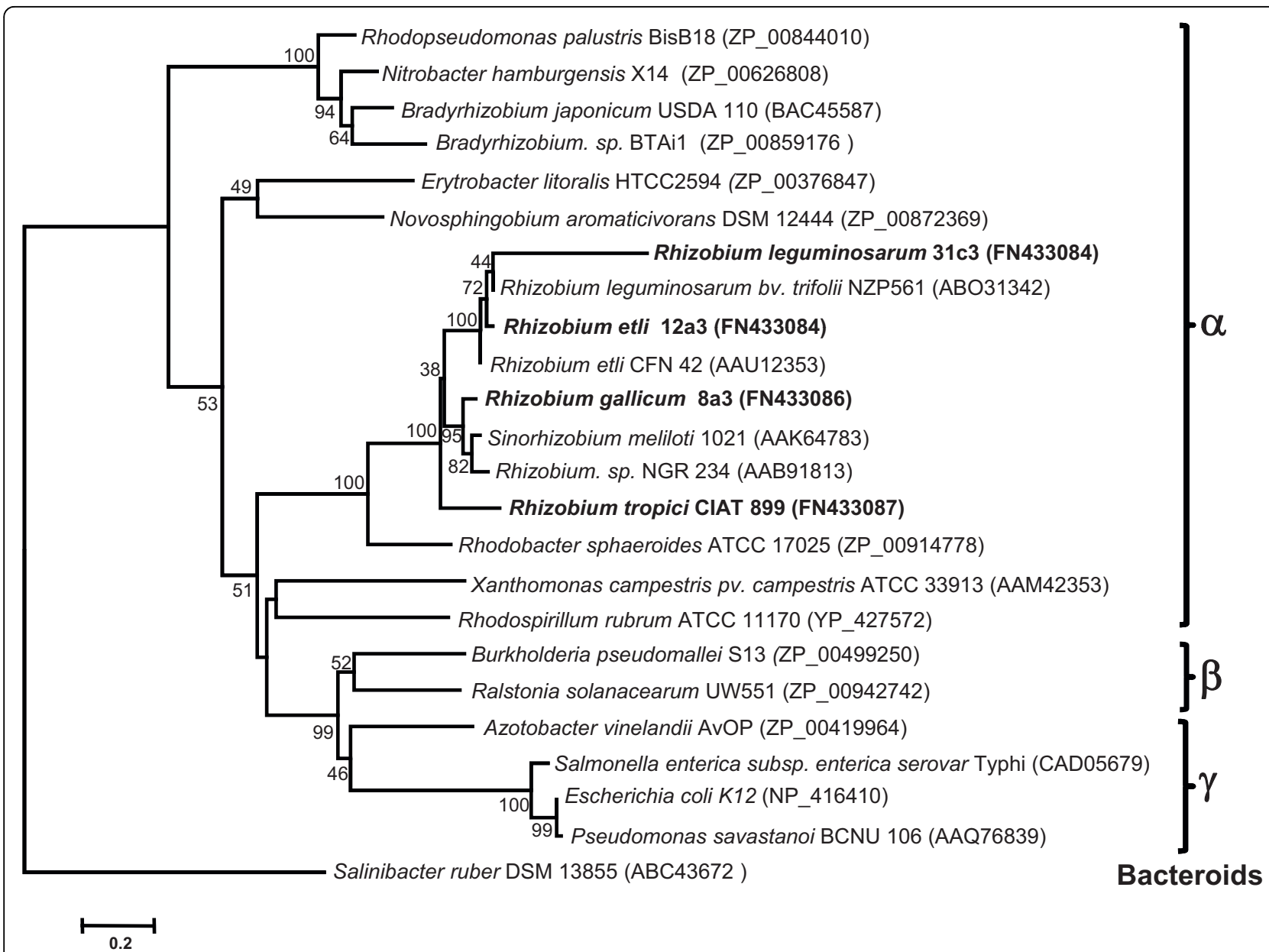

Figure 7 Neighbor-joining tree based on OtsA proteins from $\boldsymbol{\alpha}-, \boldsymbol{\beta}$-, and $\boldsymbol{\gamma}$-proteobacteria. The tree is drawn to scale, with branch lengths in the same units as those of the evolutionary distances used to infer the phylogenetic tree. The Bacteroides/Chlorobi representative $S$. ruber was used as outgroup. The evolutionary distances were computed using the Poisson correction method and are in the units of the number of amino acid substitutions per site. The rate variation among sites was modeled with a gamma distribution (shape parameter $=1$ ). All positions containing gaps and missing data were eliminated from the dataset (complete deletion option). There were a total of 287 positions in the final dataset. Bootstrap probabilities (as percentage) were determined from 1000 resamplings and values less than 30 have been omitted.

\section{Synthesis of trehalose by $R$. tropici CIAT 899 from different carbon sources}

The results presented so far indicated that trehalose is synthesized from mannitol-derived glucose via the OtsAOtsB pathway in the four Rhizobium strains tested. We were interested to know if trehalose could be also synthesized from other carbon sources. For this purpose, $R$. tropici CIAT 899 was grown in $0.1 \mathrm{M} \mathrm{NaCl} \mathrm{MAS} \mathrm{with}$ glucose, galactose, mannose and mannitol and the accumulated compounds were analyzed by ${ }^{1} \mathrm{H}$ NMR. Figure 8A-D shows that whereas the unknown sugar (later identified as a cyclic $\beta$-glucan) was synthesized from any of the tested carbon sources, trehalose was only accumulated when glucose, galactose or mannitol, but not mannose, was present in the culture medium.
To elucidate if the synthesis of trehalose by $R$. tropici CIAT 899 involves the transformation of mannitol to one or both of the trehalose glucose units, or a full degradation of the carbon source followed by a synthesis de novo, this strain was grown in $0.1 \mathrm{M} \mathrm{NaCl} \mathrm{MAS}$ medium with $1-{ }^{13} \mathrm{C}$-mannitol as carbon source, and the cellular extracts were analyzed by ${ }^{1} \mathrm{H}$ spectroscopy. As shown in Figure 8E, only resonances corresponding to the $\mathrm{C} 1$ and $\mathrm{C} 6$ carbons of the glucose units of trehalose and the unknown sugar, as well as those of the C1/C6 of mannitol, could be observed. In contrast, the three signals corresponding to glutamate were ${ }^{13} \mathrm{C}$-labelled. These findings indicate that the two glucose moieties of trehalose, as well as the unknown sugar units, were derived directly from mannitol, whereas glutamate 


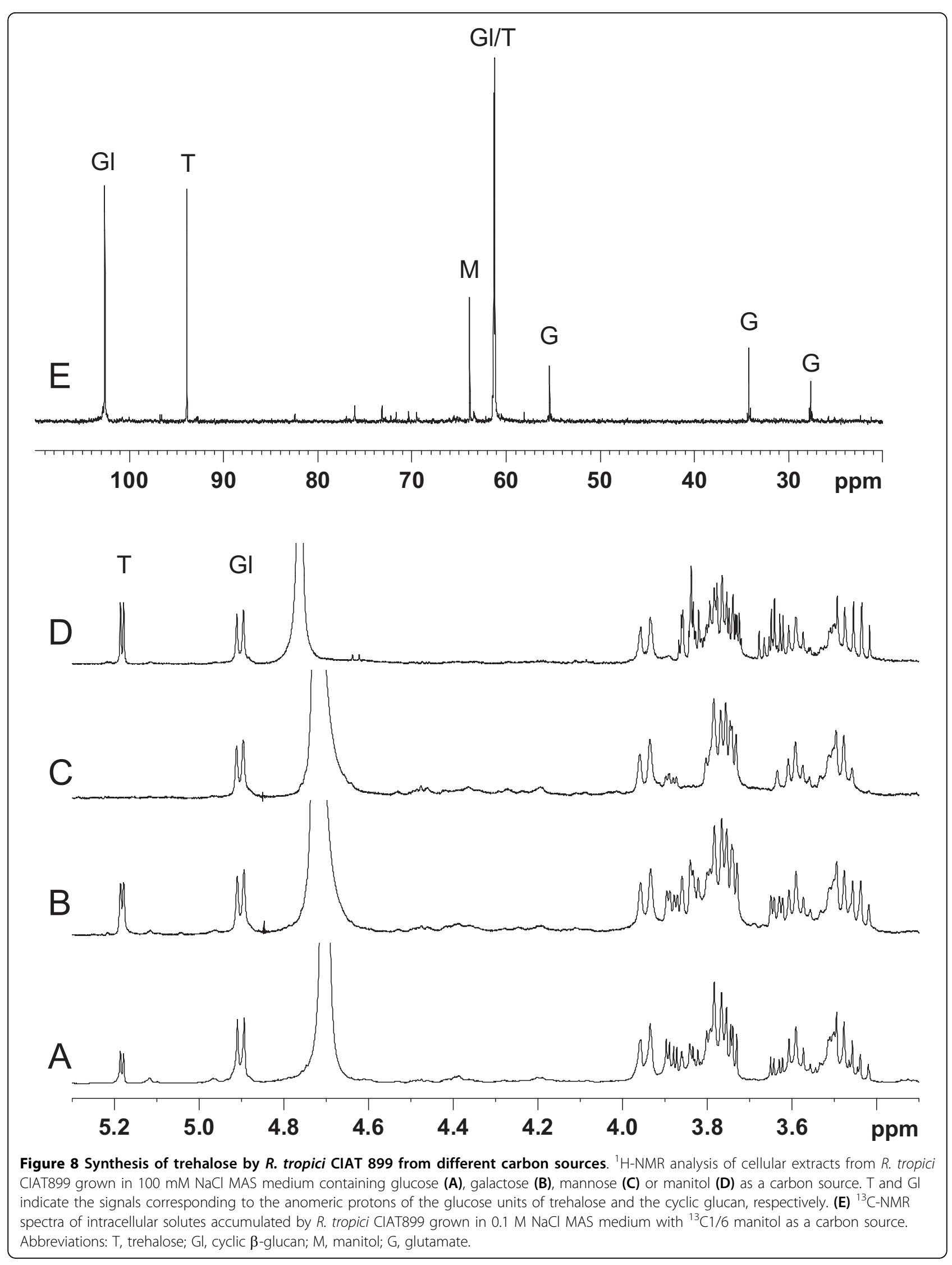


synthesis occurred de novo, after complete mannitol degradation.

\section{The unknown sugar accumulated by R. tropici CIAT 899 at low salinity is a cyclic $(1 \rightarrow 2)$ - $\beta$-glucan}

Initially, the six remaining resonances in the ${ }^{13} \mathrm{C}-\mathrm{NMR}$ spectrum of cellular extracts from $R$. tropici CIAT 899 grown at low salinity could not be assigned to any known compatible solute (see Figure 3A). To determine the structure of this unknown sugar, we took advantage of the fact that $R$. tropici grown in the presence of mannose does not synthesize trehalose, which could interfere in the identification of this compound. Thus, cells of $R$. tropici were grown in MAS medium containing 20 $\mathrm{mM}$ mannose as a carbon source, and the unknown sugar was identified by using a set of ${ }^{1} \mathrm{H}-\mathrm{NMR}, \mathrm{COSY}$, NOESY, HSQC, HMBC and MS experiments. First, in the ${ }^{1} \mathrm{H}$ spectrum, a doublet at $4.87 \mathrm{ppm}(J 7.9 \mathrm{~Hz})$ was unequivocally assigned to the anomeric hydrogen of a $\beta$-glycoside unit. Second, the combination of the COSY and NOESY spectra (not shown) and the ${ }^{1} \mathrm{H}_{-}{ }^{13} \mathrm{C}$ HSQC spectrum permitted the assignment of all proton and carbon signals in the compound (Table 1). Third, the HMBC experiment confirmed a $1 \rightarrow 2$ link between two monosaccharide, unsubstituted, molecules (Figure 9A). Finally, the mass spectrum showed a peak at $\mathrm{m} / z 1400$ corresponding to $[\mathrm{M}+\mathrm{Na}]^{++}$, from which we could deduce a molecular weight of 2754, corresponding to 17 $\beta$-glucopyranose units. On the basis of this result, the structure of the compound was established as a cyclic $(1 \rightarrow 2)$ - $\beta$-glucan formed by $17 \beta$-glucopyranose units (Figure 9B). This compound had been previously described as an extracellular glucan secreted by $R$. tropici CIAT 899 [34]. Our results clearly indicate that, as expected, the $R$. tropici CIAT 899 cyclic $(1 \rightarrow 2)-\beta$ glucan is also cell-associated.

\section{Discussion}

In this work, we investigated the osmoadaptive mechanisms used by four native rhizobia isolated from root nodules of $P$. vulgaris cultivated in north Tunisia [23]. Strains $R$. etli 12a3, R. gallicum bv. phaseoli $8 \mathrm{a} 3$ and $R$. leguminsarum $31 \mathrm{c} 3$ are potentially good inoculants as they were infective and showed efficient nitrogen fixation in symbiosis with P. vulgaris [23]. In addition, Agrobacterium $10 \mathrm{c} 2$ was able to colonize preformed $P$.

Table $1{ }^{1} \mathrm{H}$ and ${ }^{13} \mathrm{C}$ NMR data $(\delta, \mathrm{ppm})$ for the $R$. tropici CIAT 899 cyclic $(1 \rightarrow 2)$ - $\beta$-glucan

\begin{tabular}{lllllll}
\hline & $\mathbf{1}$ & $\mathbf{2}$ & $\mathbf{3}$ & $\mathbf{4}$ & $\mathbf{5}$ & $\mathbf{6}$ \\
\hline $\mathbf{H}$ & 4.87 & 3.59 & 3.79 & 3.48 & 3.52 & $3.95,3.74$ \\
$\mathbf{C}$ & 102.6 & 82.5 & 76.1 & 69.5 & 77.0 & 61.3 \\
\hline
\end{tabular}

${ }^{a}{ }^{1} \mathrm{H}$ and ${ }^{13} \mathrm{C}$ signals were referenced to internal tetramethylsilane. vulgaris nodules [28] and to specifically favour nodulation by some local strains [29], suggesting that it might be used as co-inoculant. Our results confirm the strain affiliations proposed by Mhandi et al. [24,28]. In addition, on the basis of its phylogenetic relatedness to the A. tumefaciens type strain, Agrobacterium 10c2 is proposed in this work to be renamed as A. tumefaciens 10c2.

As shown by ${ }^{13} \mathrm{C}$ - and ${ }^{1} \mathrm{H}$-NMR analyses, the longterm response of the four Rhizobium strains to $\mathrm{NaCl}$ involved the accumulation of trehalose, mannitol and glutamate; but the latter one was only observed in $R$. leguminsarum 31c3 and $R$. tropici CIAT 899. The reason why glutamate was not present in the extracts of $R$. gallicum bv. phaseoli $8 \mathrm{a} 3$ and $R$. etli $12 \mathrm{a} 3$ is unknown. It might be that glutamate is accumulated in these strains only during the early osmostress response, as the most commonly used charge counterbalance for $\mathrm{K}^{+}$influx [4], but it is subsequently replaced by trehalose. This was previously demonstrated in S. meliloti by Gouffi et al [35]. On the other hand, mannosucrose and glutamate were the main osmolytes in A. tumefaciens $10 \mathrm{c} 2$ grown at high salinity, whereas at low salt only mannitol was observed. Mannosucrose accumulation was found to be $\mathrm{NaCl}$-dependent in A. tumefaciens 10c2 (this study), $A$ tumefaciens strains C58 and NT1 [31] and in rhizobial isolates from Acacia nodules [36], supporting the hypothesis that this compatible solute participates in alleviating osmotic stress. However, isolation and analysis of osmosensitive mutants would be necessary to prove the latter statement, and additional mechanisms involved in A. tumefaciens 10c2 osmoadaptation cannot be ruled out.

In the tested strains, mannitol was not accumulated when glucose was used as a carbon source (Figure 4, and data not shown). On the other hand, cells grown with $\left[1 / 6^{13} \mathrm{C}\right]$ mannitol as a carbon source accumulated $\left[1 / 6{ }^{13} \mathrm{C}\right]$ mannitol, indicating that mannitol was not synthesized de novo but accumulated upon transport from the external medium. Bacteria rarely synthesize mannitol as a compatible solute, but it is frequent to find it as an external osmoprotectant [4]. In general, uptake and accumulation of osmoprotectants is preferred over the synthesis of endogenous compatible solutes, as the latter is energetically more costly [37]. However, $R$. tropici CIAT 899 and A. tumefaciens 10c2 used mannitol both as carbon source and as an osmoprotectant solute at low salinity, but mannitol was replaced by endogenous compatible solutes (i.e. trehalose or mannosucrose) when cells were exposed to hyperosmotic stress (see Figures 3 and 4). This finding may be explained by two, non-exclusive, reasons: (i) that trehalose and mannosucrose are better osmolytes than mannitol, and/or (ii) that energy-requiring systems, 


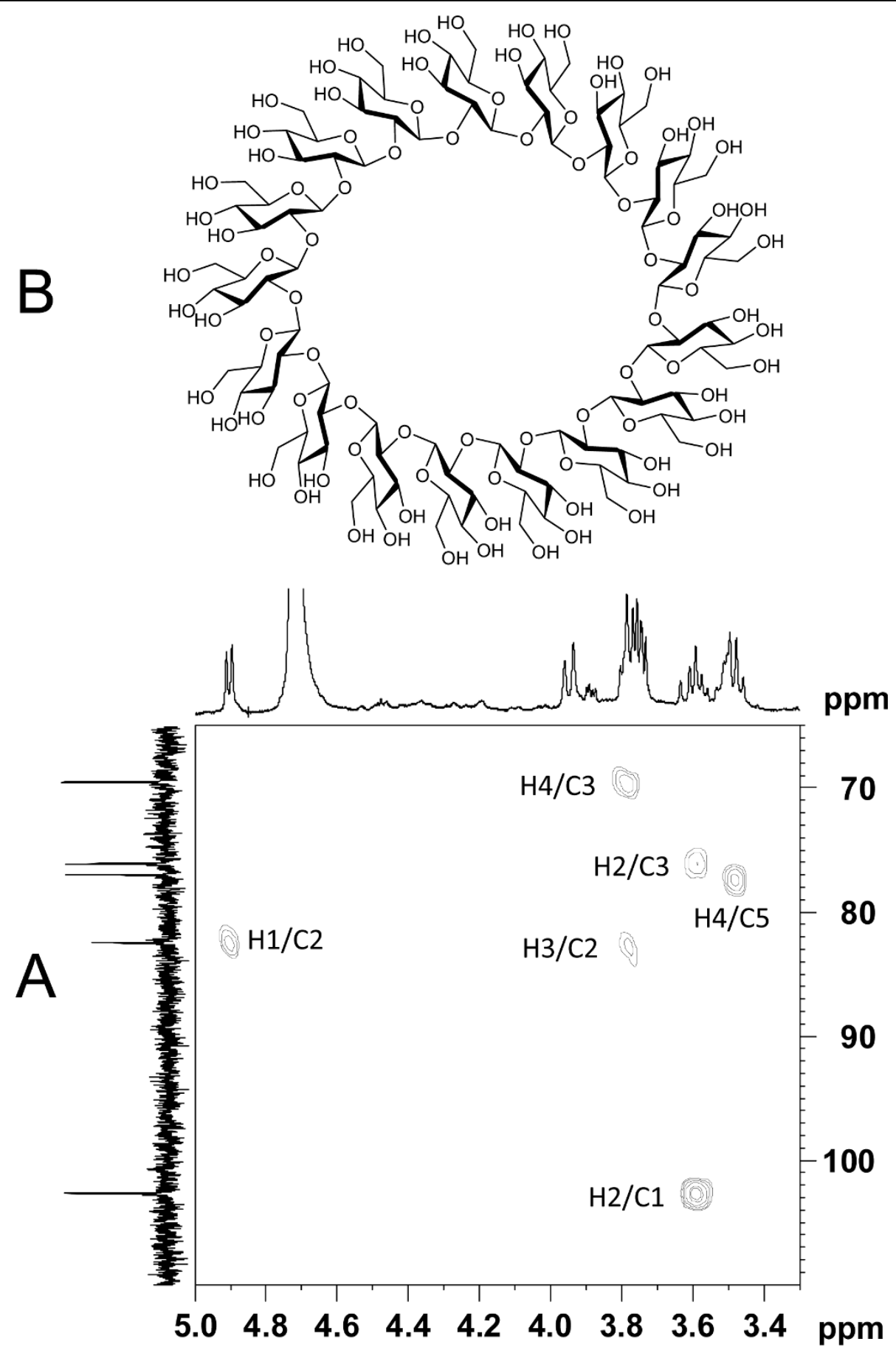

Figure 9 Identification of the $\boldsymbol{R}$. tropici CIAT899 cyclic $(\mathbf{1} \rightarrow \mathbf{2})$ - $\boldsymbol{\beta}$-glucan. (A) HMBC spectrum of intracellular solutes accumulated by $R$. tropici CIAT899 grown in MAS medium with mannose and $100 \mathrm{mM} \mathrm{NaCl}$. (B) Chemical structure of the cyclic $(1 \rightarrow 2)-\beta$-glucan.

other than trehalose or mannosucrose synthesis, were operating at high salinity, and mannitol catabolism was enhanced in detriment of its accumulation.

The role of trehalose as a compatible solute involved in bacterial tolerance to osmotic stress has been widely demonstrated in the literature. Thus, E. coli [38], S. meliloti [12] and B. japonicum [13] mutants lacking the ots $A$ gene for the synthesis of trehalose are osmosensitive. In another study, Alarico et al. [39] found a direct correlation between the presence of genes for trehalose synthesis (otsA/otsB) in Thermus thermophilus strains and their halotolerance. In this work, we found that 
trehalose synthesis in $R$. tropici CIAT 899 is osmoregulated (Figure 6), suggesting the involvement of trehalose in the osmotolerance of this strain. However, we could not find a direct correlation between the trehalose content of the rhizobial strains and their osmotolerance. On the contrary, trehalose levels in the less salt tolerant strains grown at $0.1 \mathrm{M} \mathrm{NaCl}$ were 10 fold-higher than those of the more salt-tolerant $R$. tropici CIAT 899 grown under the same conditions (Figure 6). Therefore, trehalose alone cannot account for the higher osmotolerance of $R$ tropici CIAT 899. It is improbable that accumulation of mannitol by $R$ tropici CIAT 899 conferred it a higher halotolerance, as mannitol was also accumulated by the less salt-tolerant strains. Other saltinduced responses, as modifications in the pattern of extracellular polysaccharides and lipopolysaccharides might be involved [3]. Upon transposon mutagenesis, Nogales et al [27] identified eight gene loci required for adaptation of $R$ tropici CIAT 899 to high salinity. These included genes involved in regulation of gene expression, genes related to synthesis, assembly, and maturation of proteins, and genes related with cellular buildup and maintenance.

To date, three different enzymatic pathways have been described for trehalose synthesis in rhizobia (OtsAB, TreS and TreYZ; [40]). The most common two-step OtsAB pathway catalyzes the synthesis of trehalose from UDP-glucose and glucose 6-phosphate. Trehalose synthase (TreS) catalyzes the reversible conversion of maltose and trehalose. Finally, the two-step TreYZ pathway acts in the production of trehalose from a linear maltodextrin (e.g., glycogen) [32]. In this work, we showed the presence of otsA within the genome of the four Rhizobium analyzed strains, suggesting that trehalose synthesis in these strains occurs at least via OtsAB. Synthesis of trehalose from maltooligosaccharides in $R$. tropici CIAT 899 was earlier reported [41], although TreY activity could not be detected [40]. Interestingly, the phylogenetic position of OtsA from $R$. gallicum bv phaseoli $8 \mathrm{a} 3$ and $R$. etli $12 \mathrm{a} 3$ was not consistent with the 16S rDNA-based tree, suggesting the existence of lateral transfer events. Avonce et al. [32] also found inconsistencies in the topology of a proteobacterial OtsA-based tree, and suggested to be caused by either lateral gene transfer or differential loss of paralogs.

Cyclic $(1 \rightarrow 2)-\beta$-glucans have a role in hyposmotic adaptation of the legume symbiont rhizobiaceae [8]. In $R$. tropici CIAT 899 (and probably R. gallicum bv. phaseoli $8 \mathrm{a} 3$ ) cells grown at low salinity, the cyclic $\beta$-glucan was co-extracted with the cytoplasmic compatible solute pool, suggesting that high amounts of beta glucan were present in the periplasm.. As trehalose, cyclic $(1 \rightarrow 2)-\beta$ glucans are synthesized from UDP-glucose [8]. We found that mannitol and galactose were substrates for both trehalose and the $\beta$-glucan of $R$. tropici CIAT 899 . In contrast, mannose was a substrate for the $\beta$-glucan but not for trehalose.. From the above data, we conclude that $R$. tropici CIAT 899 can convert mannitol and galactose into UDP-glucose and glucose-6-phosphate, the two trehalose precursors, but it cannot transform mannose into glucose-6-phosphate. In E. coli and other bacteria, galactose degradation pathway I (Leloir pathway) can yield both UDP-glucose and glucose-6-phosphate [42]. Thus, a similar route might be operating in $R$. tropici CIAT 899 . By using $\left[1 / 6^{-13} \mathrm{C}\right]$ mannitol as a carbon source, we showed that both trehalose moieties, as well as the $\beta$-glucan units, where derived directly from mannitol. In E. coli and other bacteria, mannitol and mannose enter the cell via specific phosphotransferase systems so the first intracellular species are mannitol-1-phosphate and mannose-6-phosphate, respectively. In a second step, these phosphoderivatives are converted by a single dehydrogenase or isomerase reaction, respectively, into the glycolytic intermediate fructose-6-phosphate, which in turn is converted to glucose-6phosphate by the action of a phosphoglucose isomerase $[43,44]$. A search in the KEGG specialized pathway database [45] showed that the genomes of $R$. etli CFN 42, $R$. leguminosarum bv. viciae 3841, S. meliloti 1021, A. tumefaciens C58, Mesorhizobium loti MAFF303099, B. japonicum USDA 110 and Rhizobium sp. NGR 234, among others, do not carry the $m$ tlA gene encoding the specific mannitol phosphotransferase, suggesting that in the Rhizobiaceae mannitol do not use a phosphotransferase system to enter the cell. Instead, we found the smoEFGK genes encoding a sorbitol/mannitol $\mathrm{ABC}$ transporter, $m t l K$ (encoding a mannitol 2-dehydrogenase that converts mannitol to fructose), and $x y l A$ (encoding a xylose isomerase that converts fructose to glucose). By analogy with these phylogenetic relatives, we suggest that in $R$. tropici mannitol could be converted into glucose via fructose. In the case of mannose, we found that the above genomes carried $\operatorname{man} X$, encoding the phosphohistidine-sugar phosphotransferase protein, suggesting that the first intracellular species is mannose-6phosphate. The gene manA, encoding the mannose-6phosphate isomerase (isomerizing mannose-6-phosphate into fructose-6-phosphate) is present in S. meliloti, Rhizobium sp. NGR 234, A. tumefaciens and B. japonicum, but not in $R$. etli, $R$. leguminosarum, or $M$. loti. This finding suggests that the latter microorganisms, and most probably $R$. tropici CIAT 899 , cannot convert mannose-6-phosphate into fructose-6-phosphate, and consequently it cannot yield glucose-6-phosphate. $R$. etli, $R$. leguminosarum and $M$. loti carried noeK, encoding a phosphomannomutase that converts mannose-6phosphate to mannose-1-phosphate, and noeJ, encoding a mannose-1-phosphate guanylyltransferase that 
converts mannose-1-phosphate to GDP-mannose, a precursor for glucan biosynthesis. In addition, $R$. tropici CIAT899 carries a noeJ-like gene, as described by Nogales et al [27]. Again by analogy with its close relatives, we suggest that a similar pathway might be operating in $R$. tropici, explaining why this microorganism can synthesize the cyclic $\beta$-glucan from mannose, but cannot convert mannose into trehalose.

\section{Conclusions}

The accumulation of compatible solutes is referred as one of the main mechanisms of bacterial tolerance to osmotic stress conditions such as salinity and drought. In this work, we found that all Rhizobium strains tested synthesized trehalose, whereas the most $\mathrm{NaCl}$-tolerant strain A. tumefaciens 10c2 synthesized mannosucrose. Whereas this finding suggests that mannosucrose might be a better compatible solute than trehalose, this would need experimental support. Despite trehalose synthesis was osmoregulated in $R$. tropici CIAT 899, our data suggest that trehalose alone cannot account for the higher osmotolerance of this strain. Thus, osmoadaptation in $R$. tropici CIAT 899 (and most soil microorganisms) is probably a complex process involving many physiological and biochemical response mechanisms, not yet fully elucidated. Although trehalose, without doubt, participates in some way to alleviate osmotic stress, there is increasing evidence that trehalose is primarily a stress metabolite designed to ensure cell survival. In fact, trehalose synthesis in E. coli is under the control of the general stress factor $\sigma^{\mathrm{S}}$, which is responsible for the expression of genes induced upon entry of stationary phase [38]. In S. meliloti, trehalose synthesis is under the control of the general stress factor RpoE2 [46], which is also necessary for desiccation resistance [47]. Thus, it may be possible that $\mathrm{NaCl}$-induced synthesis of trehalose and mannosucrose in the isolated soil strains are also involved in drought tolerance. This will be investigated in a future work.

In this work, we showed the presence of otsA within the genome of the four studied Rhizobium strains, suggesting that trehalose synthesis in these strains occurs at least via OtsAB. In addition, by using $\left[1 / 6^{-13} \mathrm{C}\right]$ mannitol as a carbon source, we showed that in $R$. tropici CIAT 899 both trehalose moieties, as well as the $\beta$-glucan units, where derived directly from mannitol. This finding, together with in silico analysis of rhizobial genomes, suggests that $R$. tropici takes up mannitol via a sorbitol/ mannitol ABC transporter. Subsequently, mannitol is converted to fructose (by a mannitol 2-dehydrogenase) and the latter one into glucose, the trehalose precursor, by a xylose isomerase. In the case of mannose, the in silico analysis suggest that $R$. tropici incorporates it through a phosphotransferase system, yielding mannose- 6-phosphate, but it cannot convert mannose-6-phosphate into fructose-6-phosphate, as it may lack the mannose-6-phosphate isomerase. This metabolic reconstruction would explain why $R$. tropici CIAT 899 cannot synthesize trehalose from mannose.

\section{Methods}

\section{Bacterial strains and growth conditions}

Bacterial strains used in this study were R. gallicum bv. gallicum 8a3, R. leguminosarum bv. phaseoli 31c3, $R$. etli 12a3, Agrobacterium sp. 10c2 (in this work renamed as $A$. tumefaciens 10c2) [23,24], and $R$. tropici CIAT $899^{\mathrm{T}}$ [15]. The reference strain $R$. tropici CIAT $899^{\mathrm{T}}$ belongs to the CIAT (International Center for Tropical Agriculture, Colombia) culture collection. It is able to form effective symbiosis with $P$. vulgaris and Leucaena trees [15] and to tolerate high temperature, low $\mathrm{pH}$, and salinity $[25,26]$. Rhizobial strains were routinely grown in complex TY medium [48] at $28^{\circ} \mathrm{C}$. For determination of salinity range and preparation of cell extracts for analysis of compatible solutes, two minimal media were used: MAS medium [49] or M79-I. M79-I is a modified M79 medium [50] in which yeast extract was substituted by $2.75 \% \mathrm{KNO}_{3}$. The basal salinity of both M79-I and MAS was $17 \mathrm{mM} \mathrm{NaCl}$. The osmotic strength of the media was increased by the addition of 50 to $600 \mathrm{mM}$ final concentrations of $\mathrm{NaCl}$. Glucose, mannitol, mannose, galactose or $1 / 6-{ }^{13} \mathrm{C}$-mannitol was used as carbon source at a final concentration of $20 \mathrm{mM}$. Growth was monitored by measuring the optical density at O.D. 600 of the cultures with a Perkin Elmer Lamda 25 UV/Vis spectrophotometer.

\section{Preparation of cell extracts, NMR spectroscopy and Mass spectrometry}

Rhizobial strains were grown in $200 \mathrm{ml}$ of M79-I or MAS minimal media up to late exponential/early stationary phase phase of growth. Carbon source and $\mathrm{NaCl}$ concentrations used varied according to the strain. Extraction of endogenous compatible solutes was performed as described by García-Estepa et al. [51]. For ${ }^{1} \mathrm{H}$ - and ${ }^{13} \mathrm{C}$-nuclear magnetic resonance (NMR) spectroscopy, dried extracts were resuspended in $\mathrm{D}_{2} \mathrm{O}(0.5$ $\mathrm{ml}$ ). NMR spectra were recorded at $25^{\circ} \mathrm{C}$ on a Bruker AV500 spectrometer at $500 \mathrm{MHz}$ for ${ }^{1} \mathrm{H}-\mathrm{NMR}$ and 125 $\mathrm{MHz}$ for ${ }^{13} \mathrm{C}-\mathrm{NMR}$. The chemical shifts are reported in $\mathrm{ppm}$ on the $\delta$ scale relative to tetramethylsilane. Signals corresponding to trehalose, glutamate, mannosucrose, and mannitol were confirmed by comparison with previously ${ }^{1} \mathrm{H}$ - and ${ }^{13} \mathrm{C}$-NMR spectra of pure compounds or published chemical shift values [31]. Signals in the NMR spectra of the unknown sugar observed in $R$. tropici CIAT 899 extracts (later on identified as a $\beta$-glucan) were assigned by using a suite of COSY (correlated 
spectroscopy), 1 D NOESY (nuclear Overhauser effect spectroscopy), HSQC (heteronuclear single-quantum coherence), and HMBC (heteronuclear single-quantum coherence) experiments. The final cyclic $(1 \rightarrow 2)-\beta$-glucan structure was determined by Mass spectrometry by using a Applied Biosystems QTRAP LC/MS/MS system (Foster City, USA) consisting of an hybrid triple quadrupole linear ion trap $\left(\mathrm{QqQ}_{\mathrm{LIT}}\right)$ mass spectrometer equipped with an electros pray ion source (Turbo IonSpray). This structure was later confirmed by literature data [34].

\section{Determination of protein content}

To estimate total cell proteins, each rhizobial strain was grown at $28^{\circ} \mathrm{C}$ in its optimal minimal medium until late exponential/early stationary phase. The same culture was used for determination of both trehalose and protein content. Cell protein content was determined by triplicate by using the "Test-tube procedure" of the bicinchoninic acid (BCA) protein assay kit (Pierce). Cell suspensions $(1 \mathrm{ml})$ were centrifuged at 13,000 rpm for 4 min and the supernatant was removed. Cell pellets were dried overnight at $100^{\circ} \mathrm{C}$ and resuspended in $1 \mathrm{ml}$ of demineralized water by shaking at room temperature for $30 \mathrm{~min}$. After addition of $2 \mathrm{ml}$ of the BCA reagent to $100 \mu \mathrm{l}$ samples, incubation was done at $37^{\circ} \mathrm{C}$ (standard protocol, working range of $20-2,000 \mu \mathrm{g}$ protein $\mathrm{ml}^{-1}$ ) or $60^{\circ} \mathrm{C}$ (enhanced protocol, working range of 5-250 $\mu \mathrm{g}$ protein $\mathrm{ml}^{-1}$ ) for $30 \mathrm{~min}$. Then, absorption of samples was measured at $562 \mathrm{~nm}$ in a Perkin Elmer Lambda 25 $\mathrm{UV} / \mathrm{Vis}$ spectrophotometer and compared to protein standards containing bovine serum albumin in a concentration range of $0-600 \mu \mathrm{g} \mathrm{ml}^{-1}$.

\section{Extraction and determination of intracellular trehalose content}

Trehalose determination was performed basically as described by Blázquez et al. [52] by the following procedure. Cell pellets from $15 \mathrm{ml}$ of early stationary phase cultures in their optimal minimal medium were washed with isotonic carbon-free medium and resuspended in 1 $\mathrm{ml}$ of the same medium. Cells were lysed by $30 \mathrm{~min}$ incubation at $95^{\circ} \mathrm{C}$ and, after centrifugation, trehalose was assayed in a $200 \mu \mathrm{l}$ total volume reaction containing $100 \mu \mathrm{l}$ of the supernatant, $90 \mu \mathrm{l}$ of $25 \mathrm{mM}$ sodium acetate buffer ( $\mathrm{pH} 5.6)$ and $0.02 \mathrm{U}$ of commercial trehalase (Sigma). For each culture sample, endogenous glucose content was monitored by performing a parallel reaction in which trehalase was substituted by water. After overnight incubation at $37^{\circ} \mathrm{C}$, glucose released by trehalose hydrolysis was determined on $150 \mu \mathrm{l}$ of the previous reaction by addition of $150 \mu \mathrm{l}$ of a glucose oxidase/peroxidase mixture (0.66 mg ml- ${ }^{1}$ ) Aspergillus niger glucose oxidase and $0.25 \mathrm{mg} \mathrm{ml}^{-1}$ horseradish peroxidase in 0.5
M phosphate buffer, pH 6.0 (Sigma) and $50 \mu \mathrm{l}$ of 2.33 $\mathrm{mg} \mathrm{ml}{ }^{1}$ o-toluidine. After $30 \mathrm{~min}$ incubation at $37^{\circ} \mathrm{C}$, $1.5 \mathrm{ml}$ of water was added to the samples and absorption was measured at $420 \mathrm{~nm}$ in a Perkin Elmer Lambda $25 \mathrm{UV} / \mathrm{Vis}$ spectrophotometer and compared to glucose standards in a concentration range of $0-300 \mu \mathrm{g} \mathrm{ml}^{-1}$. Finally, trehalose content was inferred from the glucose content by performing a standard curve with commercial trehalose (Sigma) ranging from 1 to $5 \mathrm{mM}$. Trehalose concentration was expressed as $\mu \mathrm{mol} \mathrm{mg}$ protein $^{-1}$.

\section{Isolation of the otsA and 16S rRNA genes}

Total DNA was isolated by using the CTAB method [53]. Amplification of about 1-kb of the otsA gene from $R$. gallicum bv. phaseoli 8a3, R. leguminosarum bv. phaseoli $31 \mathrm{c} 3$, and $R$. etli $12 \mathrm{a} 3$ was performed by using the primers OTA1: 5'-ATC TGG ATG GGA TGG TCG GGA-3' and OTA2: 5'-GAC ATA TTC CTT GGC AAC GAG GTT-3'. For strain CIAT 899, otsA was amplified by using the degenerated primers: OTAS1: 5'-CAT CTG GAT GGG (CT)TG GTC GG-3' and OTAS2: 5'-GGC GAC ATA TTC CTT GGC (GC)AC (GC)AG GTT-3'. The amplification protocol consisted of the following steps: initial denaturation at $94^{\circ} \mathrm{C}$ for 5 min followed by 30 cycles of denaturation ( 45 seconds at $94^{\circ} \mathrm{C}$ ), annealing $\left(45\right.$ seconds at $\left.58^{\circ} \mathrm{C}\right)$, extension $\left(1 \mathrm{~min}\right.$ at $\left.72^{\circ} \mathrm{C}\right)$, and a final extension step at $72^{\circ} \mathrm{C}$ for $10 \mathrm{~min}$. Sequencing of the otsA genes was performed by the company Newbiotechnics (NBT, Seville, Spain). PCR amplifications of the complete 16S rRNA genes were carried out as previously described [54]. The PCR products were used as templates in sequencing reactions with internal primers to get partial sequences of the 16S rRNA gene (NBT, Seville, Spain). The resulting overlapping sequences were analyzed by using the ChromasPro software (version 1.34) to assemble the complete $16 \mathrm{~S}$ rRNA gene of each strain.

\section{Phylogenetic analysis}

The 16S rRNA gene and OtsA protein sequences were used as queries for BLAST searches at the NCBI (National Center for Biotechnology Information) web server http://www.ncbi.nlm.nih.gov/. Homologous and validated (for $16 \mathrm{~S}$ rRNA) sequences showing a high degree of similarity were included in the phylogenetic analyses. 16S rRNA-based and OtsA-based phylogenetic analyses were conducted by using the MEGA 4 software [55]. Nucleotide (16SrRNA) alignments were constructed with Clustal W (1.6). The tree was constructed by using the neighbor-joining method [56] and the evolutionary distances were computed using the two-parameter method [57]. The rate variation among sites was modeled with a gamma distribution (shape parameter = 0.25 ) and all positions containing alignment gaps and 
missing data were eliminated only in pairwise sequence comparisons. The robustness of the tree branches was assessed by performing bootstrap analysis of the neighbor-joining data based on 1000 resamplings [58]. There were a total of 1469 positions in the final dataset. The partial OtsA protein-coding sequences were aligned with Clustal W (1.6) using a BLOSUM62 matrix and manually edited. The phylogenetic tree was inferred using the neighbor-joining method and the evolutionary distances were computed using the Poisson correction method. The rate variation among sites was modeled with a gamma distribution (shape parameter $=1$ ) and all the positions containing gaps and missing data were eliminated from the dataset obtaining a total of 287 positions. The robustness of the tree branches was assessed by performing bootstrap analysis of the neighbor-joining data based on 1000 resamplings.

\section{Nucleotide sequence accession numbers}

The 16S rRNA and otsA gene sequences generated in this study correspond to $R$. leguminosarum bv. phaseoli 31c3 16S rDNA [EMBL:FN433080], $R$. gallicum bv. phaseoli 8a3 16S rDNA [EMBL:FN433081], A. tumefaciens 10c2 16S rDNA [EMBL:FN433082], $R$. etli 12a3 16S rDNA [EMBL:FN43308], R. etli 12a3 otsA [EMBL: FN433084], R. leguminosarum bv. phaseoli 31c3 otsA [EMBL:FN433085], R. gallicum bv. phaseoli 8a3 otsA [EMBL:FN433086], and $R$. tropici CIAT 899 otsA [EMBL:FN433087].

\footnotetext{
Abbreviations

NMR: nuclear magnetic resonante; MHz: megahertz; TMS: tretramethylsilane COSY: correlated spectroscopy; HSQC: heteronuclear single-quantum coherente; HMBC: heteronuclear multiple-bond correlation; NOESY: nuclear Overhauser effect spectroscopy; MS: mass spectrometry
}

\section{Acknowledgements}

We thank personnel at the Biology (Modesto Carballo and Alberto García) and Mass Spectroscopy (María Eugenia Soria) services of CITIUS (General Research Services, University of Seville) for technical assistance. This research was financially supported by grants from the European Union (Aquarhiz, INCO-CT2004-509115), AECl (Agencia Española de Colaboración Internacional), Spanish Ministerio de Ciencia e Innovación (BIO2008-04117), and Junta de Andalucía (P08-CVI-03724). Cristina Fernández-Aunión and Mercedes Reina-Bueno were recipients of a fellowship from the Spanish Ministerio de Ciencia e Innovación.

\section{Author details \\ 'Department of Microbiology and Parasitology, University of Seville, Spain. ¿Laboratory of Legumes. Centre of Biotechnology of Borj Cedria, BP 901 Hammam-lif 2050, Tunisia. ${ }^{3}$ Department of Organic and Pharmaceutical Chemistry, University of Seville, Spain. ${ }^{4}$ Current Address: NEPAD/North Africa Biosciences Network. National Research Center, El Buhouth St, Dokki, Cairo, 12311 Egypt.}

\section{Authors' contributions}

CFA and TBH performed the majority of the experiments, and participated in bioinformatic analysis. FIG contributed to NMR analysis, MA performed the phylogenetic analysis. MRB performed some growth experiments and trehalose determination, JJN participated in bioinformatic analysis and figure preparation. MEA and CV conceived the study, participated in the design, coordination, bioinformatic analysis, and writing of the manuscript. All authors have read and approved the final manuscript.

Received: 24 April 2010 Accepted: 16 July 2010 Published: 16 July 2010

\section{References}

1. Zahran $\mathrm{HH}$ : Rhizobium-legume symbiosis and nitrogen fixation under severe conditions and in an arid climate. Microbiol Mol Biol Rev 1999, 63:968-989.

2. Galinski EA: Osmoadaptation in bacteria. Adv Microb Physiol 1995, 37:272-328.

3. Miller KJ, Wood JM: Osmoadaptation by rhizosphere bacteria. Annu Rev Microbiol 1996, 50:101-136

4. da Costa MS, Santos H, Galinski EA: An overview of the role and diversity of compatible solutes in Bacteria and Archaea. Adv Biochem Eng Biotechnol 1998, 61:117-153.

5. Brown AD: Microbial water stress. Bacteriol Rev 1976, 40:803-846.

6. Welsh DT: Ecological significance of compatible solute accumulation by micro organisms: from single cells to global climate. FEMS Microbiol Rev 2000, 24:263-290.

7. Santos H, da Costa MS: Compatible solutes of organisms that live in hot saline environments. Environ Microbiol 2002, 4:501-509.

8. Breedveld MW, Miller KJ: Cyclic beta-glucans of members of the family Rhizobiaceae. Microbiol Rev 1994, 58:145-161.

9. Botsford JL, Lewis TA: Osmoregulation in Rhizobium meliloti: production of glutamic acid in response to osmotic stress. Appl Environ Microbiol 1990, 56:488-494.

10. Domínguez-Ferreras A, Muñoz S, Olivares J, Soto MJ, Sanjuán J: Role of potassium uptake systems in Sinorhizobium meliloti osmoadaptation and symbiotic performance. J Bacteriol 2009, 191:2133-2143.

11. Smith LT, Pocard JA, Bernard-Smith LT, Smith GM: An osmoregulated dipeptide in stressed Rhizobium meliloti. J Bacteriol 1989, 171:4714-4717.

12. Domínguez-Ferreras A, Soto MJ, Pérez-Arnedo R, Olivares J, Sanjuán J: Importance of trehalose biosynthesis for Sinorhizobium meliloti osmotolerance and nodulation of Alfalfa roots. J Bacteriol 2009, 191:7490-7499.

13. Sugawara M, Cytryn EJ, Sadowsky MJ: Functional role of Bradyrhizobium japonicum trehalose biosynthesis and metabolism genes during physiological stress and nodulation. Appl Environ Microbiol 2010, 76:1071-1081.

14. Mclntyre HJ, Davies H, Hore TA, Miller SH, Dufour JP, Ronson CW: Trehalose biosynthesis in Rhizobium leguminosarum bv. trifolii and its role in desiccation tolerance. Appl Environ Microbiol 2007, 73:3984-3992.

15. Martínez-Romero E, Segovia L, Mercante FM, Franco AA, Graham P, Pardo MA: Rhizobium tropici, a novel species nodulating Phaseolus vulgaris L. beans and Leucaena sp. trees. Int J System Bacteriol 1991, 41:417-426.

16. Amarger N, Macheret V, Laguerre G: Rhizobium gallicum sp. nov. and Rhizobium giardinii sp. nov., from Phaseolus vulgaris nodules. Int I System Bacteriol 1997, 47:996-1006.

17. Silva C, Vinuesa P, Eguiarte LE, Souza V, Martínez-Romero E: Evolutionary genetics and biogeographic structure of Rhizobium galliucm sensu lato, a widely distributed bacterial symbiont of diverse legumes. Mol Ecol 2005, 14:4033-4050.

18. Hardarson G: Methods for enhancing symbiotic nitrogen fixation. Plant soil 1993, 152:1-17

19. Ramos $L M G$, Boddey RM: Yield and nodulation of Phaseolus vulgaris and the competitiveness of an introduced Rhizobium strain: effects of lime, mulch and repeated cropping. Soil Biol Chem 1987, 19:171-177.

20. Graham PH: Some problems of nodulation and symbiotic nitrogen fixation in Phaseolus vulgaris L.: a review. Field Crop Res 1981, 4:93-112.

21. Sessitsch A, Howieson JG, Perret $X$, Antoun H, Martínez-Romero E: Advances in Rhizobium research. Crit Rev Plant Sci 2002, 21:323-378.

22. Suárez R, Wong A, Ramírez M, Barraza A, Orozco MC, Cevallos MA, Lara M, Hernández G, Iturriaga G: Improvement of drought tolerance and grain yield in common bean by overexpressing trehalose-6-phosphate synthase in rhizobia. Mol Plant Microb Interact 2008, 21:958-966.

23. Mhamdi R, Jebara M, Aouani ME, Ghir R, Mars M: Genotypic diversity and symbiotic effectiveness of rhizobia isolated from root nodules of Phaseolus vulgaris L. grown in Tunisian soils. Biol Fertil Soils 1999, 28:313-320. 
24. Mhamdi R, Laguerre G, Aouani ME, Mars M, Amarger N: Different species and symbiotic genotypes of field rhizobia can nodulate Phaseolus vulgaris in Tunisian soils. FEMS Microbiol Ecol 2002, 41:77-84.

25. Graham PH, Draeger JK, Ferrey ML, Conroy MJ, Hammer BE, Martine E, Aarons SR, Quinto C: Acid pH tolerance in strains of Rhizobium and Bradyrhizobium and initial studies on the basis for acid tolerance of Rhizobium tropici UMR 1899. Can J Microbiol 1994, 40:198-207.

26. Riccillo PM, Muglia Cl, de Bruijn FJ, Roe AJ, Booth IR, Aguilar OM: Glutathione is involved in environmental stress responses in Rhizobium tropici, including acid tolerance. J Bacteriol 2000, 182:1748-1753.

27. Nogales J, Campos R, BenAbdelkhalek H, Olivares J, Lluch C, Sanjuán J: Rhizobium tropici genes involved in free-living salt tolerance are required for the establishment of efficient nitrogen-fixing symbiosis with Phaseolus vulgaris. Mol Plant Microb Interact 2002, 15:225-232.

28. Mhamdi R, Mrabet M, Laguerre G, Tiwari R, Aouani ME: Colonization of Phaseolus vulgaris nodules by Agrobacterium-like strains. Can J Microbiol 2005, 51:105-111.

29. Mrabet M, Mnasri B, Romdhane SB, Laguerre G, Aouani ME, Mhamdi R: Agrobacterium strains isolated from root nodules of common bean specifically reduce nodulation by Rhizobium gallicum. FEMS Microbiol Ecol 2006, 56:304-309.

30. Ramírez-Bahena MH, García-Fraile P, Peix A, Valverde A, Rivas R, Igual JM, Mateos PF, Martínez-Molina E, Velázquez E: Revision of the taxonomic status of the species Rhizobium leguminosarum (Frank 1879) Frank 1889AL, Rhizobium phaseoli Dangeard 1926AL and Rhizobium trifolii Dangeard 1926AL. $R$. trifolii is a later synonym of $R$. leguminosarum. Reclassification of the strain $R$. leguminosarum DSM 30132 (=NCIMB 11478) as Rhizobium pisi sp. nov. Int J System Evol Microbiol 2008, 58:2484-2490.

31. Smith LT, Smith GM, Madkour MA: Osmoregulation in Agrobacterium tumefaciens: accumulation of a novel disaccharide is controlled by osmotic strength and glycine betaine. J Bacteriol 1990, 172:6849-6855.

32. Avonce N, Mendoza-Vargas A, Morett E, Iturriaga G: Insights on the evolution of trehalose biosynthesis. BMC Evol Biol 2006, 6:109.

33. Styrvold OB, Kaasen I, Strøm AR: Biochemical and genetic characterization of osmoregulatory trehalose synthesis in Escherichia coli. J Bacteriol 1998, 170:2841-2849.

34. Franco-Rodríguez G, González-Jiménez I, Tejero-Mateo P, Molina-Molina J, Doblado JA, Megías M, Romero MJ: The structure and molecular mechanisms calculations of the cyclic $(1 \rightarrow 2)-\beta$-D-glucan secreted by Rhizobium tropici CIAT 899. J Mol Struct 1993, 301:211-226.

35. Gouffi K, Pichereau V, Rolland JP, Thomas D, Bernard T, Blanco C: Sucrose is a nonaccumulated osmoprotectant in Sinorhizobium meliloti. J Bacteriol 1998, 180:5044-5051

36. Essendoubi M, Brhada F, Eljamali JE, Filali-Maltouf A, Bonnassie S, Georgeault S, Blanco C, Jebbar M: Osmoadaptative responses in the rhizobia nodulating Acacia isolated from south-eastern Moroccan Sahara. Environ Microbiol 2007, 9:603-611.

37. Oren A: Bioenergetic aspects of halophilism. Microbiol Mol Biol Rev 1999, 63:334-348.

38. Strøm AR, Kaasen I: Trehalose metabolism in Escherichia coli: stress protection and stress regulation of gene expression. Mol Microbiol 1993, 8:205-210.

39. Alarico S, Empadinhas N, Simões C, Silva Z, Henne A, Mingote A, Santos H, da Costa MS: Distribution of genes for synthesis of trehalose and mannosylglycerate in Thermus spp. and direct correlation of these genes with halotolerance. Appl Environ Microbiol 2005, 71:2460-2466.

40. Streeter JG, Gómez ML: Three enzymes for trehalose synthesis in Bradyrhizobium cultured bacteria and in bacteroids from soybean nodules. Appl Environ Microbiol 2006, 72:4250-4255.

41. Streeter JG, Bhagwat A: Biosynthesis of trehalose from maltooligosaccharides in Rhizobia. Can J Microbiol 1999, 45:716-721.

42. Frey PA: The Leloir pathway: a mechanistic imperative for three enzymes to change the stereochemical configuration of a single carbon in galactose. FASEB J 1996, 10:461-70.

43. Bock A, Curtiss III R, Kaper JB, Karp PD, Neidhardt FC, Nystrom T, Slauch JM, Squires CL, (eds): EcoSal- Escherichia coli and Salmonella: Cellular and Molecular Biology.[http://www.ecosal.org], ASMOnline.

44. Empadinhas N, Marugg JD, Borges N, Santos H, da Costa MS: Pathway for the synthesis of mannosylglycerate in the hyperthermophilic archaeon
Pyrococcus horikoshii. Biochemical and genetic characterization of key enzymes. J Biol Chem 2001, 276:43580-43588.

45. KEGG: Kyoto Encyclopedia of Genes and Genomes.[http://www.genome. jp/kegg/kegg2.html].

46. Flechard M, Fontenelle C, Blanco C, Goude R, Ermel G, Trautwetter A: RpoE2 of Sinorhizobium meliloti is necessary for trehalose synthesis and growth in hyperosmotic media. Microbiology 2010, 156:1708-1718.

47. Humann JL, Ziemkiewicz HT, Yurgel SN, Kahn ML: Regulatory and DNA repair genes contribute to the desiccation resistance of Sinorhizobium meliloti Rm1021. Appl Environ Microbiol 2009, 75:446-453.

48. Beringer JE: $\mathrm{R}$ factor transfer in Rhizobium leguminosarum. $J$ Gen Microbio/ 1974, 84:188-198.

49. Brhada F, Poggi MC, Le Rudulier D: Choline and glycine betaine uptake in various strains of Rhizobia isolated from nodules of Vicia faba var. major and Cicer arietinum I.: modulation by salt, choline, and glycine betaine. Curr Microbiol 1997, 34:167-172.

50. Vincent JM: A Manual for the Practical Study of the Root-nodule Bacteria. International Biological Programme Handbook. No. 15 Blackwell Sci. Pub., Oxford 1970.

51. García-Estepa R, Argandoña M, Reina-Bueno M, Capote N, Iglesias-Guerra F, Nieto JJ, Vargas C: The ectD gene, which is involved in the synthesis of the compatible solute hydroxyectoine, is essential for thermoprotection of the halophilic bacterium Chromohalobacter salexigens. J Bacteriol 2006, 188:3774-3784.

52. Blázquez MA, Stucka R, Feldmann H, Gancedo C: Trehalose-6-P synthase is dispensable for growth on glucose but not for spore germination in Schizosaccharomyces pombe. J Bacteriol 1994, 176:3895-3902.

53. Ausubel FM, Brent R, Kinston RE, Moore DD, Seidman JG, Smith JA, Struhl K: Current Protocols in Molecular Biology. Green Publishing Associates, NY: John Wiley and Sons 1989

54. Mellado E, Moore ERB, Nieto JJ, Ventosa A: Phylogenetic inferences and taxonomic consequences of $16 \mathrm{~S}$ ribosomal DNA sequence comparison of Chromohalobacter marismortui, Volcaniella eurihalina, and Deleya salina and reclassification of $V$. eurihalina as Halomonas eurihalina comb. nov. Int J System Bacteriol 1995, 45:712-716.

55. Tamura K, Dudley J, Nei M, Kumar S: MEGA4: Molecular Evolutionary Genetics Analysis (MEGA) software version 4.0. Mol Biol Evol 2007, 24:1596-1599.

56. Saitou N, Nei M: The neighbor-joining method: a new method for reconstructing phylogenetic trees. Mol Biol Evol 1987, 4:406-425.

57. Kimura $\mathrm{M}$ : A simple method for estimating evolutionary rates of base substitutions through comparative studies of nucleotide sequences. $J$ Mol Evol 1980, 16:111-120.

58. Felsenstein J: Confidence limits on phylogenies: an approach using the bootstrap. Evolution 1985, 39:783-791.

59. Judicial Commission of the International Committee on Systematics of Prokaryotes: The genus name Sinorhizobium Chen et al. 1988 is a later synonym of Ensifer Casida 1982 and is not conserved over the latter genus name, and the species name 'Sinorhizobium adhaerens' is not validly published. Opinion 84. Int I Syst Evol Microbiol 2008, 58:1973.

doi:10.1186/1471-2180-10-192

Cite this article as: Fernandez-Aunión et al:: Biosynthesis of compatible solutes in rhizobial strains isolated from Phaseolus vulgaris nodules in Tunisian fields. BMC Microbiology 2010 10:192.

\section{Submit your next manuscript to BioMed Central and take full advantage of:}

- Convenient online submission

- Thorough peer review

- No space constraints or color figure charges

- Immediate publication on acceptance

- Inclusion in PubMed, CAS, Scopus and Google Scholar

- Research which is freely available for redistribution 